NASA/TM-2016-218912

\title{
Optimized Heat Pipe Backup Cooling System Tested With a Stirling Convertor
}

Carl L. Schwendeman and Calin Tarau

Advanced Cooling Technologies, Inc., Lancaster, Pennsylvania

Nicholas A. Schifer

Glenn Research Center, Cleveland, Ohio

William G. Anderson and Scott Garner

Advanced Cooling Technologies, Inc., Lancaster, Pennsylvania 


\section{NASA STI Program . . . in Profile}

Since its founding, NASA has been dedicated to the advancement of aeronautics and space science. The NASA Scientific and Technical Information (STI) Program plays a key part in helping NASA maintain this important role.

The NASA STI Program operates under the auspices of the Agency Chief Information Officer. It collects, organizes, provides for archiving, and disseminates NASA's STI. The NASA STI Program provides access to the NASA Technical Report Server-Registered (NTRS Reg) and NASA Technical Report ServerPublic (NTRS) thus providing one of the largest collections of aeronautical and space science STI in the world. Results are published in both non-NASA channels and by NASA in the NASA STI Report Series, which includes the following report types:

- TECHNICAL PUBLICATION. Reports of completed research or a major significant phase of research that present the results of NASA programs and include extensive data or theoretical analysis. Includes compilations of significant scientific and technical data and information deemed to be of continuing reference value. NASA counter-part of peer-reviewed formal professional papers, but has less stringent limitations on manuscript length and extent of graphic presentations.

- TECHNICAL MEMORANDUM. Scientific and technical findings that are preliminary or of specialized interest, e.g., "quick-release" reports, working papers, and bibliographies that contain minimal annotation. Does not contain extensive analysis.
- CONTRACTOR REPORT. Scientific and technical findings by NASA-sponsored contractors and grantees.

- CONFERENCE PUBLICATION. Collected papers from scientific and technical conferences, symposia, seminars, or other meetings sponsored or co-sponsored by NASA.

- SPECIAL PUBLICATION. Scientific, technical, or historical information from NASA programs, projects, and missions, often concerned with subjects having substantial public interest.

- TECHNICAL TRANSLATION. Englishlanguage translations of foreign scientific and technical material pertinent to NASA's mission.

For more information about the NASA STI program, see the following:

- Access the NASA STI program home page at http://www.sti.nasa.gov

- E-mail your question to help@sti.nasa.gov

- $\quad$ Fax your question to the NASA STI Information Desk at 757-864-6500

- Telephone the NASA STI Information Desk at 757-864-9658

- Write to:

NASA STI Program

Mail Stop 148

NASA Langley Research Center Hampton, VA 23681-2199 
NASA/TM-2016-218912

AIAA-2015-3983

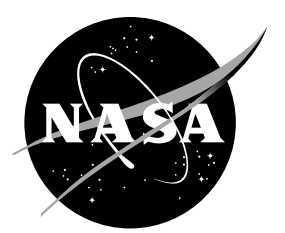

\title{
Optimized Heat Pipe Backup Cooling System Tested With a Stirling Convertor
}

\author{
Carl L. Schwendeman and Calin Tarau \\ Advanced Cooling Technologies, Inc., Lancaster, Pennsylvania \\ Nicholas A. Schifer \\ Glenn Research Center, Cleveland, Ohio \\ William G. Anderson and Scott Garner \\ Advanced Cooling Technologies, Inc., Lancaster, Pennsylvania
}

Prepared for the

13th International Energy Conversion Engineering Conference (IECEC)

sponsored by the American Institute of Aeronautics and Astronautics

Orlando, Florida, July 27-31, 2015

National Aeronautics and

Space Administration

Glenn Research Center

Cleveland, Ohio 44135 


\section{Acknowledgments}

This research was sponsored by NASA Glenn Research Center under Contract No. NNC14VC86P. Tim Wagner and Corey Wagner were ACT’s technicians for the program and constructed the VCHP prototype.

This report contains preliminary findings, subject to revision as analysis proceeds.

Level of Review: This material has been technically reviewed by technical management.

Available from

NASA STI Program

Mail Stop 148

NASA Langley Research Center

Hampton, VA 23681-2199
National Technical Information Service 5285 Port Royal Road Springfield, VA 22161 703-605-6000

This report is available in electronic form at http://www.sti.nasa.gov/ and http://ntrs.nasa.gov/ 


\title{
Optimized Heat Pipe Backup Cooling System Tested With a Stirling Convertor
}

\author{
Carl L. Schwendeman and Calin Tarau \\ Advanced Cooling Technologies, Inc. \\ Lancaster, Pennsylvania 17601 \\ Nicholas A. Schifer \\ National Aeronautics and Space Administration \\ Glenn Research Center \\ Cleveland, Ohio 44135 \\ William G. Anderson and Scott Garner \\ Advanced Cooling Technologies, Inc. \\ Lancaster, Pennsylvania 17601
}

\begin{abstract}
In a Stirling Radioisotope Power System (RPS), heat must be continuously removed from the General Purpose Heat Source (GPHS) modules to maintain the modules and surrounding insulation at acceptable temperatures. The Stirling convertor normally provides this cooling. If the Stirling convertor stops in the current system, the insulation is designed to spoil, preventing damage to the GPHS at the cost of an early termination of the mission. An alkali-metal variable conductance heat pipe (VCHP) can be used to passively allow multiple stops and restarts of the Stirling convertor by bypassing the heat during stops. In a previous NASA Small Business Innovation Research (SBIR) Program, Advanced Cooling Technologies, Inc. (ACT) developed a series of sodium VCHPs as backup cooling systems for the Stirling RPS. In 2012, one of these VCHPs was successfully tested at NASA Glenn Research Center with a Stirling convertor as an Advanced Stirling Radioisotope Generator (ASRG) backup cooling system. The prototype; however, was not optimized and did not reflect the final heat rejection path. ACT through further funding has developed a semioptimized prototype with the finalized heat path for testing at Glenn with a Stirling convertor. The semioptimized system features a two-phase radiator and is significantly smaller and lighter than the prior prototype to reflect a higher level of flight readiness. The VCHP is designed to activate and remove heat from the GPHS during stoppage with a small temperature increase from the nominal vapor temperature. This small temperature increase from nominal is low enough to avoid risking standard ASRG operation and spoiling of the multilayer insulation (MLI). The VCHP passively allows the Stirling convertor to be turned off multiple times during a mission with potentially unlimited off durations. Having the ability to turn the Stirling off allows for the Stirling to be reset and reduces vibrations on the platform during sensitive measurements or procedures. This paper presents the design of the VCHP and its test results with a Stirling convertor at Glenn. Tests were carried for multiple on and off cycles to demonstrate repeatability. The impacts associated with the addition of the VCHP to the system are also addressed in terms of mass and additional heat losses due to the presence of the VCHP.
\end{abstract}




\section{Introduction}

Advanced Stirling Radioisotope Generator (ASRG) is an attractive energy system for select space missions, and with the addition of a variable conductance heat pipe (VCHP), it becomes even more versatile. The ASRG is powered through thermal energy from decaying radioisotopes acting as General Purpose Heat Sources (GPHSs). A Stirling engine converts the thermal energy to electrical energy and cools the GPHS (Ref. 1). The Stirling convertor must operate continuously to maintain acceptable temperatures of the GPHS and protect their cladding. The addition of alkali-metal VCHP allows the Stirling to cycle on and off during a mission and can be used as a backup cooling system. The benefits of being able to turn the Stirling off are allowing for a restart of the Stirling and reducing vibrations for sensitive measurements.

\section{Concept Introduction}

The conceptual VCHP for a Stirling convertor has four critical components: an evaporator, a first condenser, a second condenser, and a noncondensable gas (NCG) reservoir as shown in Figure 1(a). The VCHP is atypical because of the presence of two condensers. The working fluid is sodium and is shown in red (Fig. 1) starting at the GPHS and ending at the NCG front. The NCG is shown in blue (Fig. 1) starting at the front and ending in the reservoir. The VCHP evaporator interfaces with the GPHS modules and transfers thermal energy to one of the condensers. The first condenser is located at the Stirling's heater head and is active only if the Stirling convertor is operating. The second condenser is a radiator between the heater head and the NCG reservoir that is active when the Stirling is off, as shown in Figure 1(b). The radiator rejects the heat generated by the GPHS to the cold-side adaptor flange (CSAF). The NCG reservoir is located after the second condenser. The VCHP was tested as a backup cooling system for the Stirling (Ref. 2). The details of how the VCHP operates are described below.

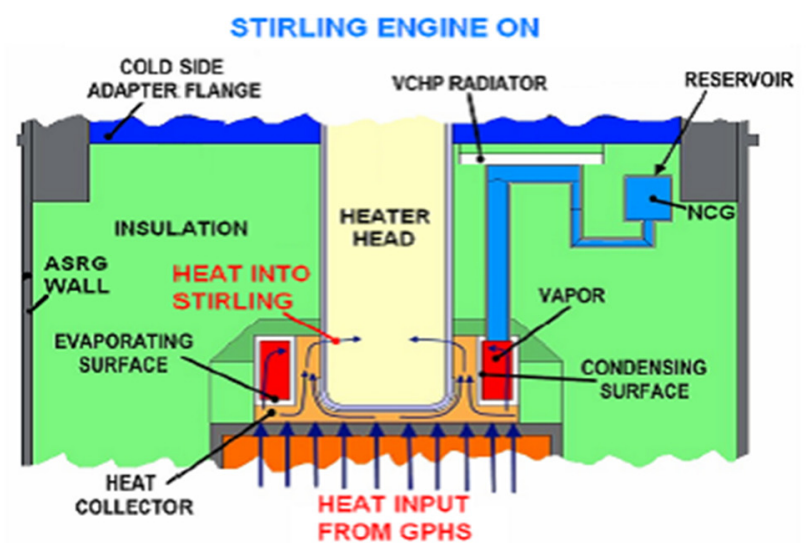

(a)

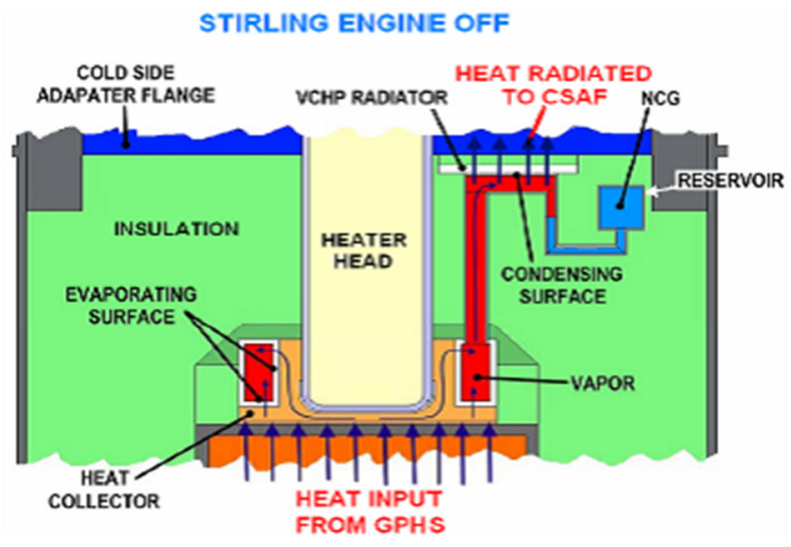

(b)

Figure 1.-Advanced Stirling Radioisotope Generator (ASRG) backup cooling concept. The front location is depicted for an operating convertor (a) and a nonoperating convertor (b) (Ref. 3). 


\section{ASRG Backup Cooling System}

The VCHP acting as a backup cooling system has two heat rejection or condenser locations, depending on whether the Stirling is on or off. The two condenser locations are shown in Figures 1(a) and (b); the VCHP is shown in red and blue; the red depicts the hot sodium vapor; and the blue represents the colder NCG. The VCHP wraps annularly around the heat collector attached to the Stirling heater head. The predicted location of the front is shown in Figure 1 for each stage. Heat is input to the Stirling when it is operational and the front is before the VCHP radiator (second condenser) as shown on the left in Figure 1(a). When the Stirling is turned off, the sodium vapor temperature will rise slightly and sweep the NCG out of the second condenser for utilization as a radiator. In the ASRG backup cooling concept, the CSAF would be used as the heat sink. The front will recede when the Stirling is turned back on and the vapor temperature will drop returning the system to the initial state. The Stirling is cycled on and off to demonstrate repeatability and the recovery of the system parameters. The Stirling convertor as tested has the heat collector up and not down as shown in the illustrations.

\section{Stirling Convertor}

The Stirling convertor used for this test was an Advanced Stirling Convertor (ASC-1HS \#2) developed by Sunpower, Inc., under contract with NASA Glenn Research Center as a technology development project. The 80- $\mathrm{W}_{\mathrm{e}}$-class ASC-1 HS \#2 arrived at Glenn in November 2007 and has accumulated over 6,500 hr of operation in Glenn's Stirling Research Lab. It is a hermetically sealed unit, with the exception of the helium fill tube, that can reach $850^{\circ} \mathrm{C}$ with a high-strength cast superalloy 247LC heater head that allows for higher hot-end temperatures. The convertor is shown in Figure 2 in the vertical (heater head up) test position.

The ASC heater head is covered by a brazed nickel 201 heat collector. Substantial effort for test preparation focused on obtaining an accurate fit between the outside diameter (OD) of the heat collector and the inside diameter (ID) of the VCHP. At Glenn, the OD of the convertor's heat collector was reduced from 59.72 to $42.26 \mathrm{~mm}$ to allow for a smaller and lighter VCHP. Machining of the heat collector also reduced the contact surface roughness allowing for uniform gap between the Stirling and VCHP. After the OD of the heat collector was defined, the VCHP inner diameter was machined to at least $42.72 \mathrm{~mm}(0.076 \mathrm{~mm},-0.000 \mathrm{~mm})$. A minimal gap between the VCHP and Stirling heat collector helped reduce the thermal contact resistance between the components. Boron nitride paste was used to coat the OD of the ASC heat collector and the ID of the VCHP to assist in thermal transfer between the two surfaces and to prevent galling during VCHP removal.

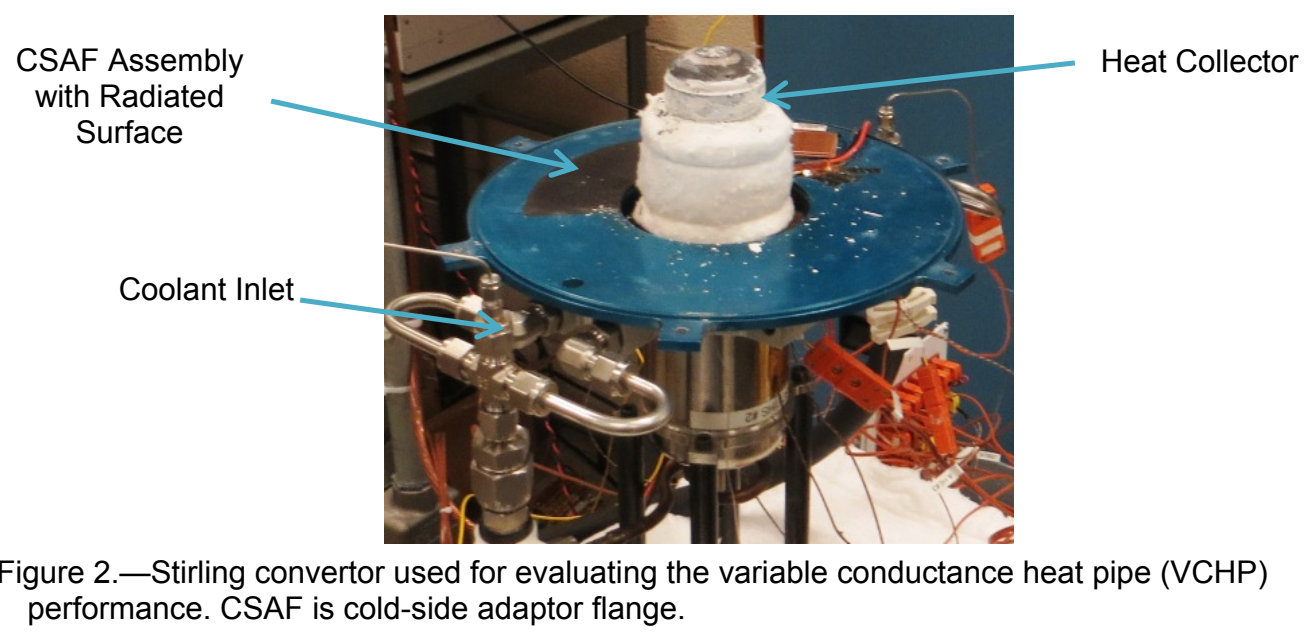




\section{VCHP Prototype Layout and Design}

The VCHP was designed to slide over the Stirling's heat collector as shown in the Figure 3 crosssectional view. The slip fit was selected to simulate the geometry of flight-ready hardware that could be brazed directly to the Stirling hot end without the need of a heat collector. Thermal power is supplied to the system by eight cartridge heaters embedded in the nickel heater cylinder shown (Fig. 3). The heater cylinder and VCHP are under a compressive load supplied by a spring assembly to decrease the contact resistance. The heater cylinder and spring compression assembly are commonly used by Glenn on this type of Stirling convertor and were suitable to use with the VCHP configuration with minimal modification. The heat supplied by the cartridge heaters is transferred to the upper surface of the VCHP where the sodium working fluid evaporates and condenses on the inner wall of the VCHP if the Stirling convertor is operating. If the Stirling is off, then the heat will be transferred to the radiator (that is not shown in Fig. 3).

The VCHP installed on the Stirling convertor layout is shown in Figures 4 and 5. The VCHP annulus is shown connecting to the radiator with a $9.5-\mathrm{mm}\left(0.38\right.$-in.) outer diameter tube that has a $90^{\circ}$ downward bend. The tube connects to the radiator near the edge to allow for a larger distance from the radiator inlet to the radiator outlet. The larger distance between the radiator inlet and outlet is helpful in location of the VCHP front during operation and reducing heat leaks from the annulus to the radiator. The radiator geometry arcs around the CSAF to allow for a conformal configuration. There is an air gap between the radiator and the CSAF assembly as shown in Figure 6, the side view, to ensure radiation is the dominate mode of heat transfer from the radiator to the CSAF. Using radiation to transfer heat from the VCHP to the CSAF assembly helps reduce the heat leaks from the VCHP to the CSAF when the Stirling convertor is operating. The radiator is connected to the reservoir by a $6.35-\mathrm{mm}(0.25$-in.) tube that helps thermally isolate the reservoir from the hot radiator when it is active. However, the reservoir is cooled slightly by the CSAF through a copper shim between the bottom surface of the reservoir and upper surface of the CSAF assembly (shim is not shown in the figure) to maintain the reservoir's temperature. The VCHP was charged with sodium and NCG through the vent valve, which was left on the test system to allow for dynamic modification of the NCG charge during testing. In a flight-ready system the valve would be removed and the VCHP would be hermetically sealed before flight. The valve is located outside of the insulation housing and goes through an existing slot in the insulation housing.

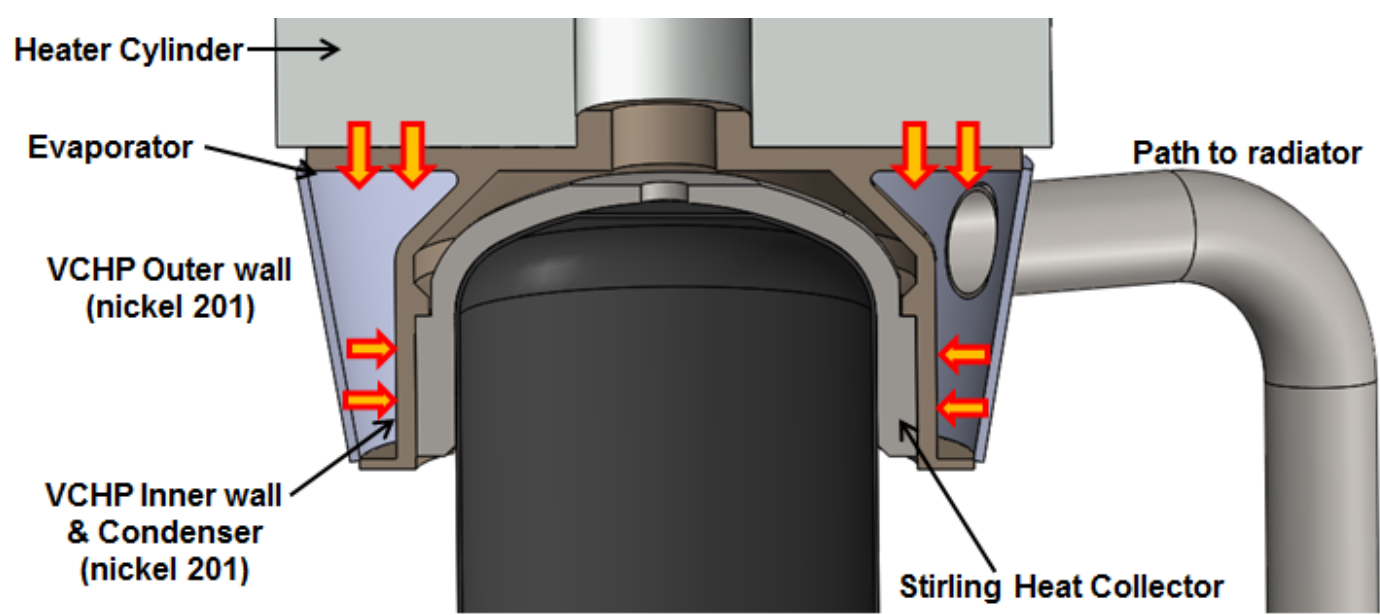

Figure 3.-Cross section of the Stirling hot end, variable conductance heat pipe (VCHP) annulus, and heater cylinder after assembly. 


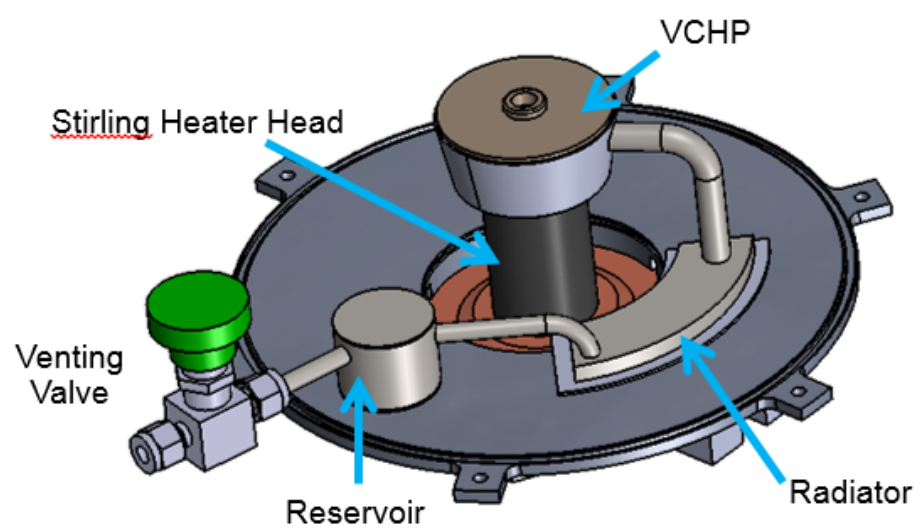

Figure 4.-Variable conductance heat pipe (VCHP) installed on the Stirling convertor.

\section{Side View}

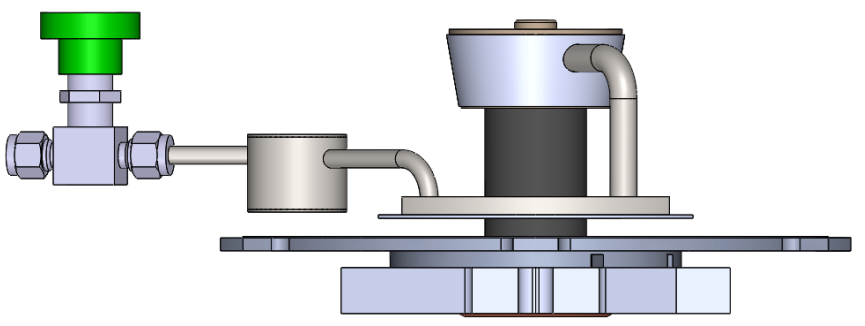

Top View

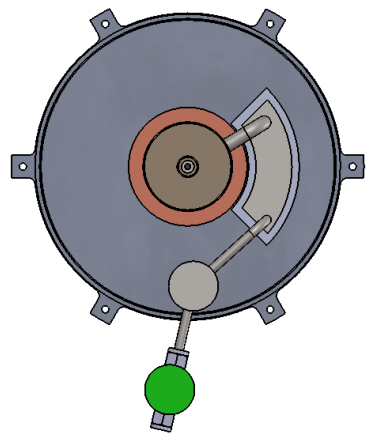

Figure 5.—Variable conductance heat pipe (VCHP) layout side and top views.

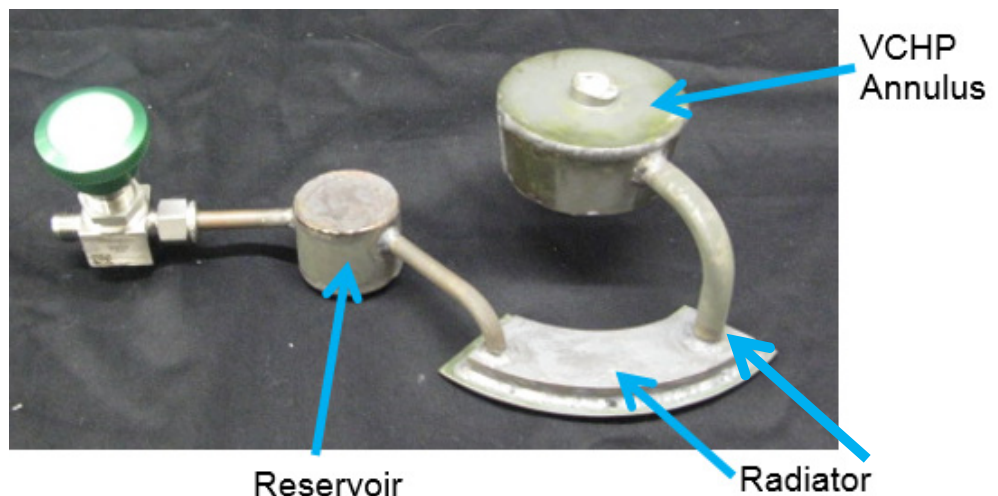

Figure 6.-Variable conductance heat pipe (VCHP) as constructed after heat cycling.

The VCHP as built is shown in Figure 6. The VCHP was welded together out of nickel 201 and stainless steel. The VCHP annulus is entirely nickel 201 to match the coefficient of thermal expansion (CTE) of the Stirling's heat collector. The connecting tubes are stainless steel as are the upper surface of the radiator and the entire reservoir. The lower face of the radiator is nickel 201, which was selected for its high thermal conductivity and acceptable strength in the working temperature range. The VCHP wall thicknesses were designed with a minimum factor of safety (FoS) of 2 against yielding to maintain a reasonably light but robust prototype. The VCHP mass as built is $358 \mathrm{~g}(0.79 \mathrm{lb})$ including the sodium charge and screen. 


\section{Experimental Configuration}

The testing setup is shown in Figure 7 with the VCHP and Stirling convertor assembled. The VCHP mounts on the Stirling heat collector after which the heater cylinder, heater hardware, insulation, and insulation housing are installed. The test position is vertical with the heater head up to accommodate the fixture of the Stirling convertor. The final test configuration with insulation and thermocouples (TCs) connected is shown in Figure 7(b).

The TC map for the VCHP is shown in Figure 8. There are 4 TCs on the annulus, 5 on the tube that connect the annulus to the radiator, 4 on the top of the radiator, 4 on the tube that connects the radiator to the NCG reservoir, and 2 on the NCG reservoir for a total of 18 TCs on the VCHP. However, TC 102 located on the annulus became detached prior to testing and its readings were not relevant. The TCs are spot welded onto the surface and used to record the VCHP temperature and locate the NCG front during operation. Additional TCs are located on the significant components of the system including TC 101-a probe in the heater block, TC 121 - an adhesive TC located on the aluminum flange below the radiated surface, and TC 122 - an adhesive TC located in the copper section of the CSAF assembly. Additional measurements were recorded by NASA Glenn's system including the heat collector temperature, coolant inlet and outlet temperatures, and the insulation housing temperature.

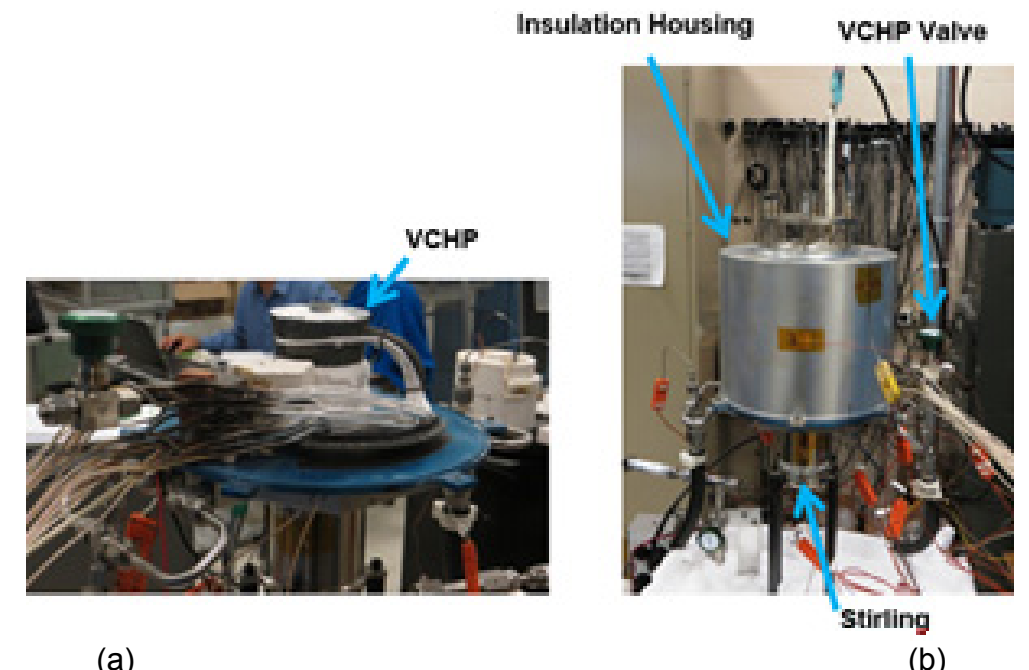

(a)

(b)

Figure 7.-Testing setup with variable conductance heat pipe (VCHP) and Stirling convertor assembled. (a) VCHP installed on Stirling convertor. (b) VCHP and insulation housing installed on the Stirling convertor.

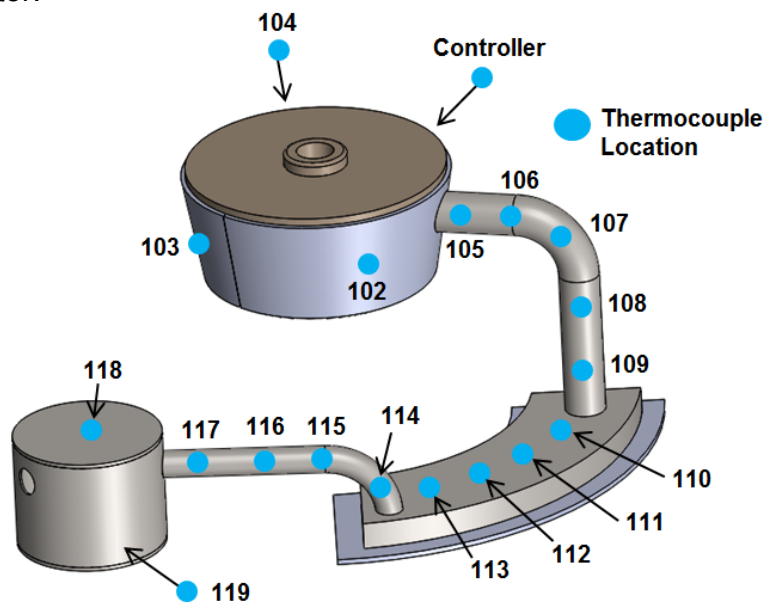

Figure 8.-Variable conductance heat pipe (VCHP) thermocouple (TC) map. 


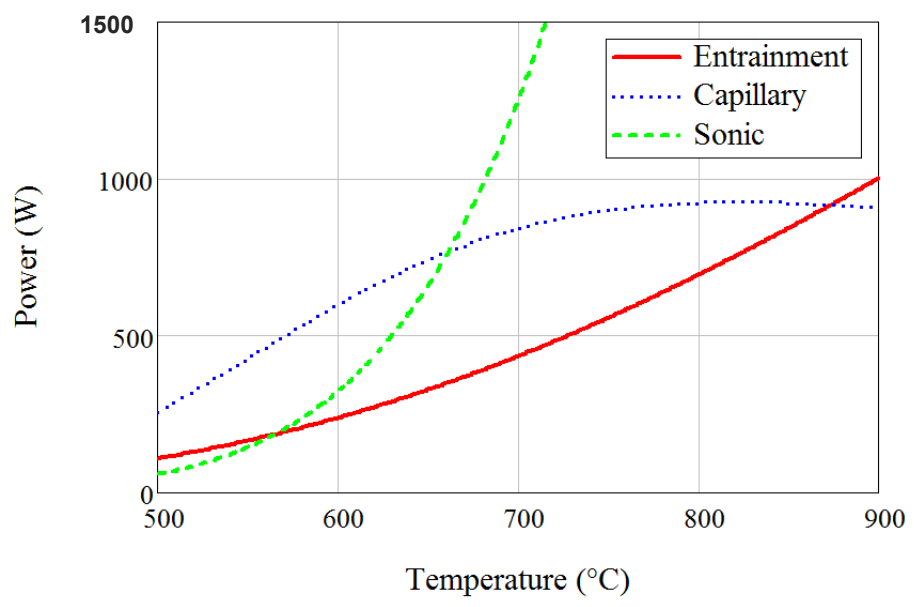

Figure 9.-Theoretical heat pipe capacity limits.

\section{Modeling}

Modeling of the VCHP consists of two parts: modeling of the heat pipe performance and modeling of the gas charge behavior. Modeling the heat pipe performance consisted of optimizing the heat pipe's geometry to carry the desired power with a reasonable FoS. To optimize the heat pipe's performance the screen mesh count was optimized based on capillary performance for the heat pipe. Then the heat pipe was evaluated for the capillary, entrainment, and sonic limits. These limits are represented in Figure 9 as a function of temperature. Entrainment and sonic limits have a FoS of 2 and the capillary limit has a FoS of 1.33. The desired carrying capacity of the heat pipe was $250 \mathrm{~W}$ in the temperature range of 750 to $850^{\circ} \mathrm{C}$. As shown the heat pipe had a FoS of over 2 in the working temperature range.

The VHCP model was developed during a prior project for NASA Glenn and assumed a flat front between the NCG and sodium vapor. The model evaluates the required temperature increase in the sodium vapor to compress the NCG and activate the radiator for the given VCHP geometry when the Stirling convertor is turned off. Modeling of the VCHP consisted primarily of iterating the reservoir's geometry and reducing the radiator's internal volume to maintain a temperature increase to activate the radiator on the order of $35^{\circ} \mathrm{C}$.

\section{Experimental Results}

The following three main experiments were carried out at NASA Glenn:

1. Heat losses determination - to properly evaluate the amount of heat that is transferred through the heat collector.

2. Long-duration stoppage - to evaluate the VCHP — Stirling convertor interaction during an indefinite period of stoppage.

3. Multiple short-duration stoppages - to evaluate the capacity of the system to return to nominal temperatures after each stoppage during a multiple stoppage regime. 


\section{Heat Losses Determination}

Heat losses through the insulation were determined by incrementally applying power to the heaters just enough to maintain the vapor in the VCHP at the nominal temperature of $780^{\circ} \mathrm{C}$. The actual value of the heat losses was $123 \mathrm{~W}$. As a result, the total electrical power applied to the heaters was $348 \mathrm{~W}$, to ensure that the heat collector will accept $\sim 225 \mathrm{~W}$.

\section{Long-Duration Stoppage of the Stirling Convertor}

The experimental results for the long-duration stoppage experiment are shown in Figure 10 for a single off cycle of the Stirling convertor where steady state was achieved in each stage. The data shown is the raw data collected except for the input power that was held constant during the experiment at $348 \mathrm{~W}$ moderated by a proportional integral derivate (PID) controller. The Stirling is on during stage $1(1,100$ to $15,360 \mathrm{~s}$ ) and the VCHP radiator temperatures are reasonably low at an average of $210^{\circ} \mathrm{C}$. Both sodium vapor and heater reach steady-state values of 779 and $886^{\circ} \mathrm{C}$, respectively, while the Stirling heat collector has a steady-state temperature of $694^{\circ} \mathrm{C}$ given the thermal resistance across the gap between the VCHP and Stirling. The Stirling convertor is turned off at approximately $15,360 \mathrm{~s}$ starting stage $2(15,360$ to 20,594 s). When the Stirling convertor is off the VCHP temperature and sodium vapor pressure rise rapidly, compressing the NCG in the reservoir and activating the radiator. There is a temperature gradient present in the radiator as it is slightly oversized and the sodium vapor does not need to occupy the entire radiator to reject the bypass heat. The Stirling is cycled back on at 20,594 s starting the nominal system recovery, stage $3(20,594$ to $29,600 \mathrm{~s})$. The radiator temperatures drop rapidly as the front is retracted out of the radiator until it settles back into the annulus. As seen during stage 3, all the temperatures return to their initial values prior to the Stirling shutdown.

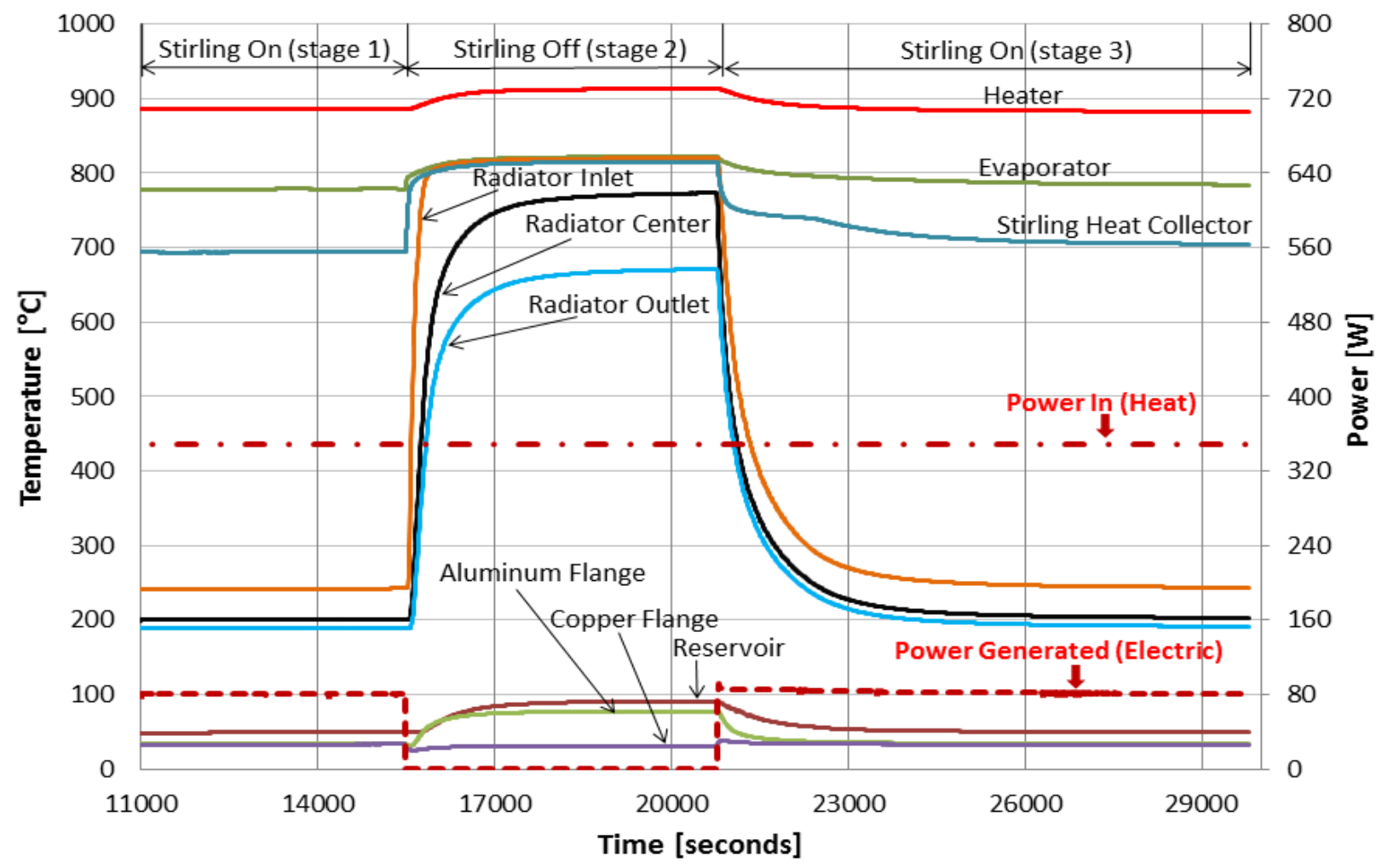

Figure 10.-Experimental results for the long-duration stoppage test where steady states are achieved. 
The steady-state temperature distribution of the VCHP with the Stirling on (stage 1) is shown in Figure 11. The evaporator is approximately isothermal and the temperature drops rapidly down the heat pipe due to the NCG front in the $9.53-\mathrm{mm}(0.38$-in.) connecting tube. The reservoir temperature is only slightly hotter than the aluminum or copper flange portions of the CSAF assembly. Figure 12 shows the steady-state temperature distribution during stage 2, when the Stirling convertor is off. The connecting tube and radiator are significantly hotter as the front was pushed out into the radiator to facilitate heat rejection. The evaporator temperature increased to $822^{\circ} \mathrm{C}$ from approximately $779{ }^{\circ} \mathrm{C}$ to provide the necessary pressure to compress the NCG into the reservoir. However, the temperature increase of the reservoir is minimal. Given the evaporator's temperature rise, the heat source (heater) also experienced a similar temperature increase. The temperature of the Stirling convertor's heat collector rose to $815^{\circ} \mathrm{C}$ as it became an adiabatic component surrounded by the evaporator. Overall, the temperature profiles match the generally expected performance of the VCHP.

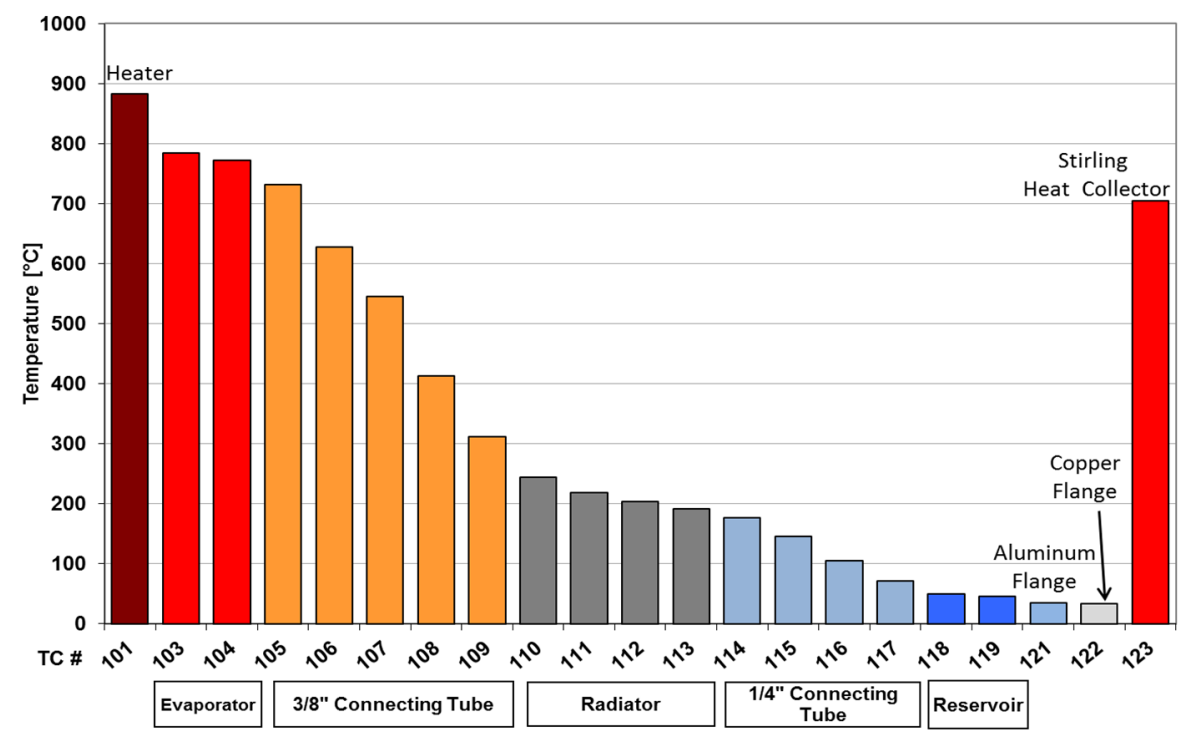

Figure 11.-Steady-state temperature profile during stage 1 (at 29,794 s) when Stirling convertor is on.

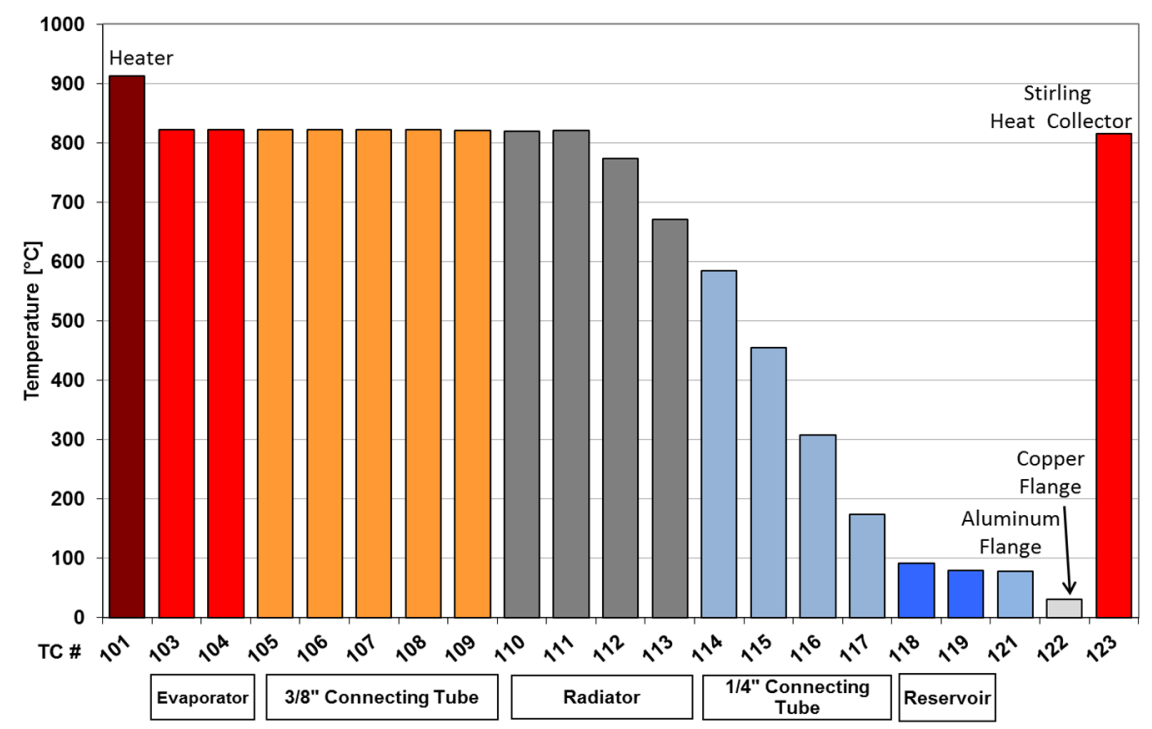

Figure 12.- Steady-state temperature profile during stage 2 (at 20,574 s) when Stirling convertor is off. 


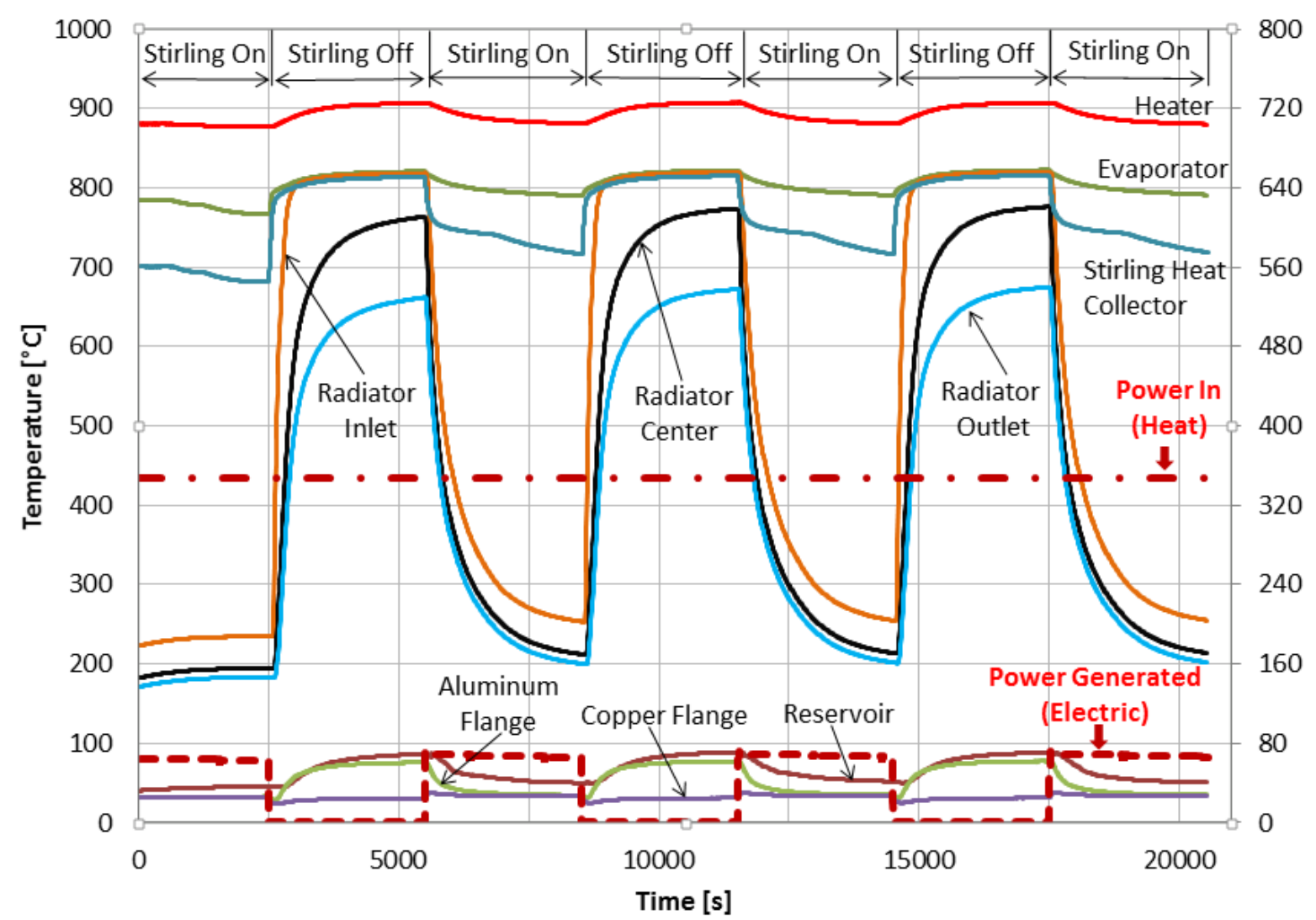

Figure 13.-Experimental results for the multiple short-duration stoppages testing of the Stirling convertor with variable conductance heat pipe (VCHP).

\section{Multiple Short-Duration Stoppages of the Stirling Convertor}

The experimental results for the multiple short-duration stoppages testing are shown in Figure 13 where the Stirling convertor was cycled off three times demonstrating the repeatability of the VCHP behavior. The time between each stage is approximately $50 \mathrm{~min}$. to show the general trend towards a steady-state event though it is not reached. Overall, the testing results show that the VCHP can assist Stirling convertor's on and off regime reliably and with full repeatability.

\section{Conclusion}

The optimized variable conductance heat pipe (VCHP) was successfully tested with the Stirling convertor and achieved the test objectives. Acting as a backup cooling system the VCHP was able to bypass the input heat when the Stirling was shut off without exceeding the maximum allowable heat collector temperature and return to the initial state when the Stirling convertor was restarted. Additional objectives with the testing and design were to minimize the VCHP mass and heat leaks associated with the addition of the VCHP. The VCHP was reasonably light at $358 \mathrm{~g}(0.79 \mathrm{lb})$, but could be further optimized by using super alloys and specific geometries. The heat leak associated with the addition of the VCHP were minimal at $5 \mathrm{~W}$; however, it could be further reduced by increasing the length of the connecting tube to the radiator as well as by using specific geometries, consistent with mass reduction. The heat leak associated with the addition of the VCHP was tested by using a solid annulus of nickel that represented the VCHP annulus but did not have the connecting tubes, radiator, or reservoir. Overall the VCHP can be introduced into Stirling convertor-powered configurations with a feasible projected weight and heat loss cost. 


\section{References}

1. Chan, J.; Wood, J.G.; and Schreiber, J.G.: Development of Advanced Stirling Radioisotope Generator for Space Exploration. Paper presented at Space Technology and Applications International ForumStaif 2007, Albuquerque, NM, 2007.

2. Tarau, C., et al.: Variable Conductance Heat Pipe Operated With Stirling Convertor. Paper presented at the 11th International Energy Conversion Engineering Conference, San Jose, CA, 2013.

3. Tarau, C.; and Anderson, W.G.: Sodium Variable Conductance Heat Pipe for Radioisotope Stirling Systems - Design and Experimental Results. Paper presented at the 11th International Energy Conversion Engineering Conference, Nashville, TN, 2010. 


